\title{
Axial length measurement acquisition rates of two optical biometers in cataractous eyes
}

This article was published in the following Dove Press journal:

Clinical Ophthalmology

22 July 2014

Number of times this article has been viewed

\section{Alice Epitropoulos}

The Ohio State University Wexner Medical Center, Columbus, OH, USA
Purpose: To compare the ability of two optical biometers to acquire the axial length (AL) measurement in cataractous eyes.

Methods: This prospective, comparative, single-center study comprised 105 eyes (63 patients). $\mathrm{AL}$ was acquired by the composite mean value of 20 measurements (composite-20 IM) and five measurements (composite-5 IM) (IOLMaster ${ }^{\circledR} 500$ version 7.1 software), and the standard mean value of the first five measurements (standard-5 LS, Lenstar LS $900^{\circledR}$ ). Anterior chamber depth (ACD) and average keratometry $(\mathrm{K})$ readings were acquired.

Results: AL was acquired in $83.8 \%, 92.4 \%$, and $84.8 \%$ of eyes for the composite- 5 IM, composite-20 IM, and standard-5 LS, respectively. Standard-5 LS AL measurements were significantly shorter $(P<0.001)$. IOLMaster ${ }^{\circledR} 500$-acquired ACD (corneal epithelium to lens) measurements were significantly shorter $(P<0.001)$. IOLMaster ${ }^{\mathbb{B}} 500$ average $\mathrm{K}$ measurements were significantly steeper $(P<0.001)$.

Conclusion: The composite-20 IM had the highest AL acquisition success rate of the three versions evaluated. AL, ACD, and average Ks were statistically different between the two biometers, although the differences were clinically insignificant.

Keywords: cataract, biometry, IOL power calculation

\section{Introduction}

Axial length (AL) measurement is a crucial aspect in predicting correct intraocular lens (IOL) power. The advent of new premium implant technologies has increased patient expectations for exceptional postoperative vision, in turn decreasing the acceptable margin for error in IOL power calculation. Achieving successful outcomes postoperatively, then, requires accurate preoperative measurement of AL.

Typically, AL measurement is undertaken with optical biometry. ${ }^{1}$ The IOLMaster $^{\mathbb{R}}$ optical biometry system (Carl Zeiss Meditec AG, Jena, Germany) uses partial coherence interferometry (PCI) and has been studied in the use of calculating IOL powers..$^{2-5}$ This technology has been shown to have excellent intraobserver and interobserver reliability, with extremely high precision and performance accuracy. ${ }^{2,3,6-16}$ The Lenstar LS $900^{\circledR}$ (Haag-Streit AG, Koeniz, Switzerland) is a second optical biometer that uses optical low-coherence reflectometry. This technology has also been shown to provide reliable and accurate measurements similar to PCI. ${ }^{1,17-19}$ In clinical practice, it is fairly common to use these devices interchangeably with the presumption that similar results will be obtained for all types of cataract grades.

Although dense cataracts may limit the ability of optical biometers to measure the AL, software and hardware upgrades have decreased acquisition failure substantially. ${ }^{18,20}$ Buckhurst et al $^{18}$ reported AL was not measurable in $9 \%$ to $10 \%$ of eyes using either the Lenstar ${ }^{\circledR}$ or the IOLMaster ${ }^{\circledR}$ version 5 software in cataract
Correspondence: Alice Epitropoulos

The Ohio State University Wexner Medical Center, 262 Neil Avenue,

Columbus, $\mathrm{OH} 43215$, USA

Tel + I 6I422I 7464

Email aepitrop@columbus.rr.com 
patients. However, Hill et $\mathrm{al}^{20}$ reported a $96.3 \%$ overall success in acquiring AL with the IOLMaster ${ }^{\circledR}$ using version 5 software, with the failures attributed to dense cataracts, specifically with posterior subcapsular (PSC) cataracts.

The purpose of this study was to compare the AL measurement acquisition rates of the IOLMaster ${ }^{\circledR} 500$ (using version 7.1 software) with both the composite mean value of 20 measurements (composite-20 IM) and five measurements (composite-5 IM) readings to the AL measurement acquisition rate of the Lenstar LS $900^{\circledR}$ (using the standard mean value of the first five measurements [standard-5 LS]) in eyes with cataracts and to educate clinicians about the potential differences in reliability and repeatability between the two when measuring identical cataract densities. Cataracts were classified and graded according to morphology and density.

\section{Patients and methods}

This study comprised 105 eyes of 63 consecutive patients scheduled for cataract extraction in one or both eyes at The Eye Center of Columbus, Columbus, OH, USA. The study conformed to the Declaration of Helsinki and was approved by the Research Consultants Review Committee Institutional Review Board (Austin, TX, USA). Patients were prospectively recruited and signed consent forms. Inclusion criteria required that patients be scheduled for cataract extraction in one or both eyes.

Patients were excluded from the study if they had a physical inability to position at the slit lamp biomicroscope or biometry device (ie, head tremor), inability to open the eyelid widely enough so all measurements could be performed, inability to fixate due to ocular disease (eg, macular degeneration, amblyopia), corneal or media opacities other than cataract that may cause acquisition failure (eg, corneal scar, vitreous condensation), or an active ocular infection or inflammation of the eye.

Preoperative biometric measurements were obtained in all patients using two measurement algorithms with the IOLMaster $^{\circledR} 500$ and one algorithm with the Lenstar ${ }^{\circledR}$. In addition to $\mathrm{AL}$, anterior chamber depth (ACD) and keratometry (K) readings were obtained. The IOLMaster ${ }^{\circledR}$ keratometer projects six spots of light onto the cornea in a hexagonal pattern with a diameter of $2.5 \mathrm{~mm}$. The Lenstar ${ }^{\circledR}$ measures $\mathrm{Ks}$ at $2.30 \mathrm{~mm}$ and $1.65 \mathrm{~mm}$ (most manual keratometers measure $3.0 \mathrm{~mm}$ diameter). Cataracts were graded and classified using the Lens Opacities Classification III scoring system (LOCS III) ${ }^{21}$ by a single LOCS III-certified examiner (AE). A complete ophthalmic examination was performed on all patients, including the measurement of uncorrected distance visual acuity and corrected distance visual acuity, best corrected visual acuity (BCVA), and slit lamp and fundus examination.

\section{Biometric measurements}

Both the IOLMaster ${ }^{\circledR} 500$ and the Lenstar ${ }^{\circledR}$ measure AL, anterior corneal radii, $\mathrm{ACD}$, and the corneal diameter (CD) in the human eye. Additionally, the Lenstar ${ }^{\circledR}$ measures pupil size and corneal, lens, and retinal thickness; the LS 900 is the only optical biometer that measures lens thickness (LT). New formulas, such as the Hoffer H, Hoffer H-5, Holladay 2, and Olsen, use LT as one of the variables for calculating IOL power; LT has been suggested as particularly useful in short eyes. Surgeons using these formulas and the IOLMaster ${ }^{\text {B }}$ 500 need to measure LT in a separate step with immersion ultrasound biometry or estimate it by patient age. ${ }^{1,18}$

The IOLMaster ${ }^{\circledR} 500$ and Lenstar LS $900^{\circledR}$ differ in how $\mathrm{AL}$ is acquired. Whereas the Lenstar ${ }^{\circledR}$ compiles an average of all recorded measurements, the IOLMaster ${ }^{\mathbb{B}} 500$ applies noise reduction filtering to each individual scan, attenuating the variable noise in each measurement while calculating the composite signal. The IOLMaster ${ }^{\circledR} 500$ offers an AL calculation algorithm that utilizes a composite of 20 scans and the Lenstar ${ }^{\circledR}$ measures five individual scans.

For this study, AL measurements reported using the Lenstar ${ }^{\circledR}$ algorithm were referred to as "standard," and AL measurements reported using the IOLMaster ${ }^{\circledR} 500$ software algorithm were referred to as "composite." The following describes the measurements recorded for each study eye:

1. Standard mean value of the first five measurements (standard-5 LS) refers to the average AL measurement calculated by the Lenstar ${ }^{\circledR}$ after the operator performed five measurements with the device.

2. Composite mean value of the first five measurements (composite-5 IM) refers to the composite AL measurement calculated after taking five measurements with the IOLMaster $^{\circledR} 500$ with version 7.1 software.

3. Composite mean value of 20 measurements (composite- 20 IM) refers to the composite AL measurement calculated after taking 20 measurements with the IOLMaster ${ }^{\circledR} 500$ with version 7.1 software.

In steps 2 and 3, only one set of readings was performed with the IOLMaster ${ }^{\circledR} 500$; the technician recorded the first five readings and continued with the remainder for the composite-20.

The sequence of measurement acquisition with the devices alternated between study eyes. Two examiners performed all the tests according to the manufacturers' device recommendations. The examiners also recorded the time required by each device to acquire the measurements. 
The Accutome A-Scan Synergy ultrasound unit was used to measure AL in the study eyes that were not measurable with

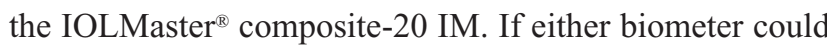
not acquire $\mathrm{AL}$, we did an immersion scan.

\section{Statistical analysis}

The AL measurement acquisition rates were calculated for each of the three measurement methods and compared using the McNemar Test. For each measurement method, the AL availability was stratified according to nuclear color, nuclear opalescence, cortical grade, and PSC opacity, which were determined using the LOCS III grading system. The Fisher exact test was performed to compare the AL availabilities across different cataract grades of nuclear color, nuclear opalescence, cortical grade, and PSC. The mean, standard deviation, and the range of the $\mathrm{AL}, \mathrm{ACD}$, and average $\mathrm{K}$ measurements for both instruments were summarized and compared using the paired $t$-test.

All statistical analyses were performed using SAS software (version 9.1.3, SAS Institute, Inc., Cary, NC, USA).

\section{Results}

The mean age of the patients was $71.1 \pm 0.5$ years (range, $38-90$ years). The preoperative BCVA was $20 / 40$ or better in $74 \%$ of eyes and $20 / 200$ or worse in $11 \%$. The mean spherical equivalent in all eyes was $-0.15 \pm 2.63 \mathrm{D}$ (range, $-7.00 \mathrm{D}$ to $+6.50 \mathrm{D})$. The average time required to take all the measurements on the Lenstar LS $900^{\circledR}$ was $5.88 \pm 0.19$ minutes $(95 \%$ confidence interval [CI], 5.50-6.25) compared to $4.50 \pm 0.16$ minutes (95\% CI, 4.18-4.81) with the IOLMaster ${ }^{\circledR} 500$ $(P<0.001)$. All patients in the study had more than one type of cataract (mixed cataracts).
There was no statistically significant difference in the success rate of acquiring AL measurements between the standard-5 LS and composite-5 IM methods (84.8\% versus $83.8 \%$, respectively; $P=0.782$ ). However, the composite- 20 IM method was statistically significantly more successful at acquiring $\mathrm{AL}$ measurements (92.4\%) compared with the standard-5 LS $(P=0.011)$ and composite-5 IM methods $(P=0.003)$.

Table 1 shows the AL measurement availability for each of the three measurement methods stratified by cataract type and grade. Of the three measurement methods, the composite-20 IM method had the most consistent success for AL measurements across different cataract grades. The standard-5 LS and composite-5 IM methods were able to acquire AL measurements successfully in $30 \%$ of eyes with a cataract nuclear color graded $>5.0$, whereas the composite-20 IM was able to acquire AL measurements successfully in $60 \%$ of eyes with a cataract nuclear color graded $>5.0$. These data were not powered to detect a statistical significance due to the small number of patients with cataracts with a nuclear color $>5.0$ on the LOCS III scale $(n=10)$.

Similarly, the composite-5 IM had the lowest success for AL measurement for cortical grades $>4.2$ (Table 1). The composite-5 IM was successful in $25 \%$ of cataracts with cortical grades $>4.2$, compared with $41.6 \%$ and $58.3 \%$ with the standard-5 LS and composite-20 IM, respectively. The standard-5 LS had the lowest overall success for AL measurement in PSC cataracts. In the densest PSC cataracts (grades 4.2 to 5.9), the standard-5 LS and composite-5 IM were successful in $48.2 \%$ and $59.2 \%$ of cases, respectively, compared with $70.4 \%$ in the composite- 20 IM method.

Table I Axial length acquisition

\begin{tabular}{|c|c|c|c|}
\hline $\begin{array}{l}\text { Cataract type } \\
\text { and grade (LOCS III) }\end{array}$ & $\begin{array}{l}\text { Lenstar }^{\circledR} \text { (standard-5 } \\
\text { LS) } n / \mathbf{N}(\%)\end{array}$ & $\begin{array}{l}\text { IOLMaster }{ }^{\circledR} \text { (composite-5 } \\
\text { IM) n/N (\%) }\end{array}$ & $\begin{array}{l}\text { IOLMaster }^{\circledR} \text { (composite-20 } \\
\text { IM) n/N (\%) }\end{array}$ \\
\hline \multicolumn{4}{|l|}{ PSC } \\
\hline$\leq 4.2$ & 75/77 (97.2) & $71 / 77(92.2)$ & $77 / 77(100)$ \\
\hline$>4.2$ & I3/27 (48.3) & 16/27 (59.2) & 19/27 (70.4) \\
\hline \multicolumn{4}{|l|}{ Cortical cataract } \\
\hline$\leq 4.2$ & $83 / 92(90.2)$ & $84 / 92(91.3)$ & $89 / 92(96.7)$ \\
\hline$>4.2$ & $5 / 12(4 \mid .6)$ & $3 / 12(25)$ & $7 / 12(58.3)$ \\
\hline \multicolumn{4}{|l|}{ Nuclear color } \\
\hline$\leq 5.0$ & $85 / 94(90.4)$ & $84 / 94(89.4)$ & 90/94 (95.7) \\
\hline$>5.0$ & $3 / 10(30)$ & $3 / 10(30)$ & $6 / 10(60)$ \\
\hline \multicolumn{4}{|l|}{ Nuclear opalescence } \\
\hline$\leq 5.0$ & $83 / 93(89.3)$ & $83 / 93(89.3)$ & 89/93 (95.7) \\
\hline$>5.0$ & $5 / 11(45.5)$ & 4/II (36.4) & $7 / 11(63.6)$ \\
\hline
\end{tabular}

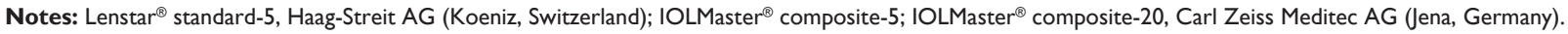
Abbreviations: LOCS, Lens Opacities Classification III scoring system; PSC, posterior subcapsular cataract; $n$, number of patients where the device was able to successfully obtain an axial length; $\mathrm{N}$, total number of patients in each of the groups. 
The ability to successfully acquire AL varied by device and acquisition algorithm. Overall, AL could not be measured in seven of 105 eyes with either device (Table 2). The IOLMaster ${ }^{\circledR} 500$ was successful in acquiring $\mathrm{AL}$ in nine eyes that the Lenstar ${ }^{\circledR}$ (standard-5 LS) was not capable of measuring successfully. The standard-5 LS was able to acquire $\mathrm{AL}$ in one eye that could not be acquired with either the composite-5 IM or the composite-20 IM. Immersion ultrasound measurement in this eye yielded a $0.51 \mathrm{~mm}$ longer AL compared with the standard-5 LS measurement. The patient received an implant based on the immersion scan and had an emmetropic result.

The difference in AL with both devices is illustrated in Figure 1. The measurements acquired by the standard-5 LS method were statistically significantly longer $(P=<0.001)$ compared with the composite-5 IM and composite-20 IM. These differences are not likely to be clinically significant. The difference in $\mathrm{K}$ readings acquired with the two devices is illustrated in Figure 2. The differences in ACD with the two devices are illustrated in Figure 3. These differences are not likely to be clinically significant. There was no difference between the two composite methods ( $P=0.871$ ).

Table 3 shows the differences between the two biometers in mean ACD and average $\mathrm{K}$ data. Although ACD values are slightly longer and average $\mathrm{K}$ measurements were slightly flatter with the Lenstar ${ }^{\circledR}$ compared to the IOLMaster $^{\circledR} 500(P<0.001)$, the difference is not likely to be clinically relevant, but the variation may be. Table 4 shows the differences in AL measurement, when both eyes could be assessed by both devices.

\section{Discussion}

Previous studies have shown that the AL cannot be measured with the IOLMaster ${ }^{\circledR}$ in $4 \%$ to $18 \%$ of eyes with a dense cataract. ${ }^{7,11,14,22,23}$ Although density grading and morphology is unavailable in many of these studies, the presence of PSC opacities has been shown to significantly affect the ability to measure AL. ${ }^{20,22,23}$ Dense nuclear sclerotic and PSC cataracts are commonly reported causes of acquisition failure, $7,11,20,22,23$ which is consistent with the findings in the current study. However, as we took AL measurements at the center of the

Table 2 Acquisition failures, Lenstar ${ }^{\circledR}$ and IOLMaster ${ }^{\circledR}$

\begin{tabular}{|c|c|c|c|c|c|c|c|c|c|c|}
\hline $\begin{array}{l}\text { Subject } \\
\text { number }\end{array}$ & Eye & Age & $\begin{array}{l}\text { Nuclear } \\
\text { color* }\end{array}$ & $\begin{array}{l}\text { Nuclear } \\
\text { opalescence* }\end{array}$ & Cortical* & PSC* & $\begin{array}{l}\text { IOL Master }^{\circledR} \\
\text { (composite-5 } \\
\text { IM) }(\mathrm{AL}, \mathrm{mm})\end{array}$ & $\begin{array}{l}\text { IOL Master }^{\circledR} \\
\text { (composite-20 } \\
\text { IM) }(\mathrm{AL}, \mathrm{mm})\end{array}$ & $\begin{array}{l}\text { Lenstar }^{\circledR} \\
\text { (standard-5 LS) } \\
\text { (AL, mm) }\end{array}$ & $\begin{array}{l}\text { Immersion } \\
\text { ultrasound } \\
(\mathrm{AL}, \mathrm{mm}) \\
\end{array}$ \\
\hline \multicolumn{11}{|c|}{ Both IOLMaster ${ }^{\circledast} 00$ and Lenstar ${ }^{\circledast}$ failed } \\
\hline 2 & OS & 65 & 5.6 & 6.2 & 5.9 & 5.9 & & & & 22.62 \\
\hline 3 & OD & 84 & 6.2 & 5.9 & 3.9 & 5.6 & & & & 24.77 \\
\hline 8 & OD & 81 & 3.5 & 2.9 & 5.3 & 4.3 & & & & 24.61 \\
\hline 8 & OS & 81 & 3.4 & 2.9 & 4.9 & 5.9 & & & & 24.26 \\
\hline 11 & OD & 80 & 4.9 & 4.6 & 3.2 & 5.9 & & & & 24.94 \\
\hline 16 & OS & 61 & 6.9 & 6.8 & 5.9 & 5.9 & & & & 23.39 \\
\hline 45 & OD & 65 & 6.9 & 6.9 & 5.9 & 5.9 & & & & 23.05 \\
\hline \multicolumn{11}{|c|}{ IOLMaster ${ }^{\circledast} 500$ failed but Lenstar ${ }^{\circledast}$ succeeded $^{-}$} \\
\hline 23 & OD & 63 & 3.4 & 4.4 & 0.7 & 5.3 & & & 21.47 & 21.98 \\
\hline \multicolumn{11}{|c|}{ IOLMaster ${ }^{\circledast} 500$ succeeded but Lenstar $^{\circledast}$ failed } \\
\hline 7 & OS & 79 & 3.6 & 2.9 & 4.8 & 5.9 & 23.84 & 23.82 & & \\
\hline 17 & OS & 83 & 3.7 & 3.6 & 2.8 & 3.9 & & 23.11 & & \\
\hline 22 & OD & 80 & 3.8 & 4.3 & 3.9 & 5.9 & 22.24 & 22.22 & & \\
\hline 38 & OD & 84 & 5.9 & 5.8 & 2.7 & 4.2 & 23.31 & 23.27 & & \\
\hline 48 & OD & 39 & 2.2 & 1.9 & 1.5 & 4.9 & 22.63 & 22.60 & & \\
\hline 56 & OS & 65 & 3.2 & 2.4 & 1.8 & 5.3 & & 26.67 & & \\
\hline 62 & OD & 78 & 5.1 & 4.3 & 2.9 & 4.9 & 24.63 & 24.55 & & \\
\hline 65 & OS & 80 & 6.6 & 6.9 & 5.9 & 5.9 & & 22.25 & & \\
\hline 67 & OD & 44 & 2.3 & 2.1 & 2.1 & 5.5 & 23.32 & 23.32 & & \\
\hline \multicolumn{11}{|c|}{ 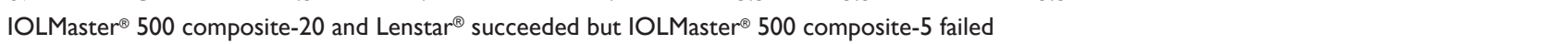 } \\
\hline 14 & OS & 74 & 4.1 & 3.9 & 0.4 & 2.9 & & 23.25 & 23.25 & \\
\hline 26 & OD & 81 & 3.4 & 3.4 & 5.2 & 0.3 & & 23.35 & 23.38 & \\
\hline 26 & OS & 81 & 3.4 & 3.2 & 5.3 & 0.1 & & 23.13 & 23.14 & \\
\hline 31 & OD & 81 & 3.3 & 3.2 & 2.6 & 0.9 & & 24.21 & 24.13 & \\
\hline 38 & OS & 84 & 5.7 & 5.1 & 2.8 & 3.8 & & 23.20 & 23.17 & \\
\hline 43 & OD & 62 & 5.2 & 5.7 & 5.9 & 5.9 & & 22.03 & 22.01 & \\
\hline
\end{tabular}

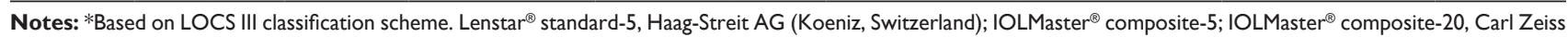
Meditec AG (Jena, Germany).

Abbreviations: AL, axial length; LOCS, Lens Opacities Classification III scoring system; OD, right eye; OS, left eye; PSC, posterior subcapsular cataract. 
Agreement on axial length between Lenstar ${ }^{\circledR}$ and IOLMaster ${ }^{\circledR} 500$ (composite-20 IM) $3 / 89=3.37 \%$ outside the limits of agreement

Mean difference 0.021

$95 \%$ limits of agreement $(-0.033,0.075)$

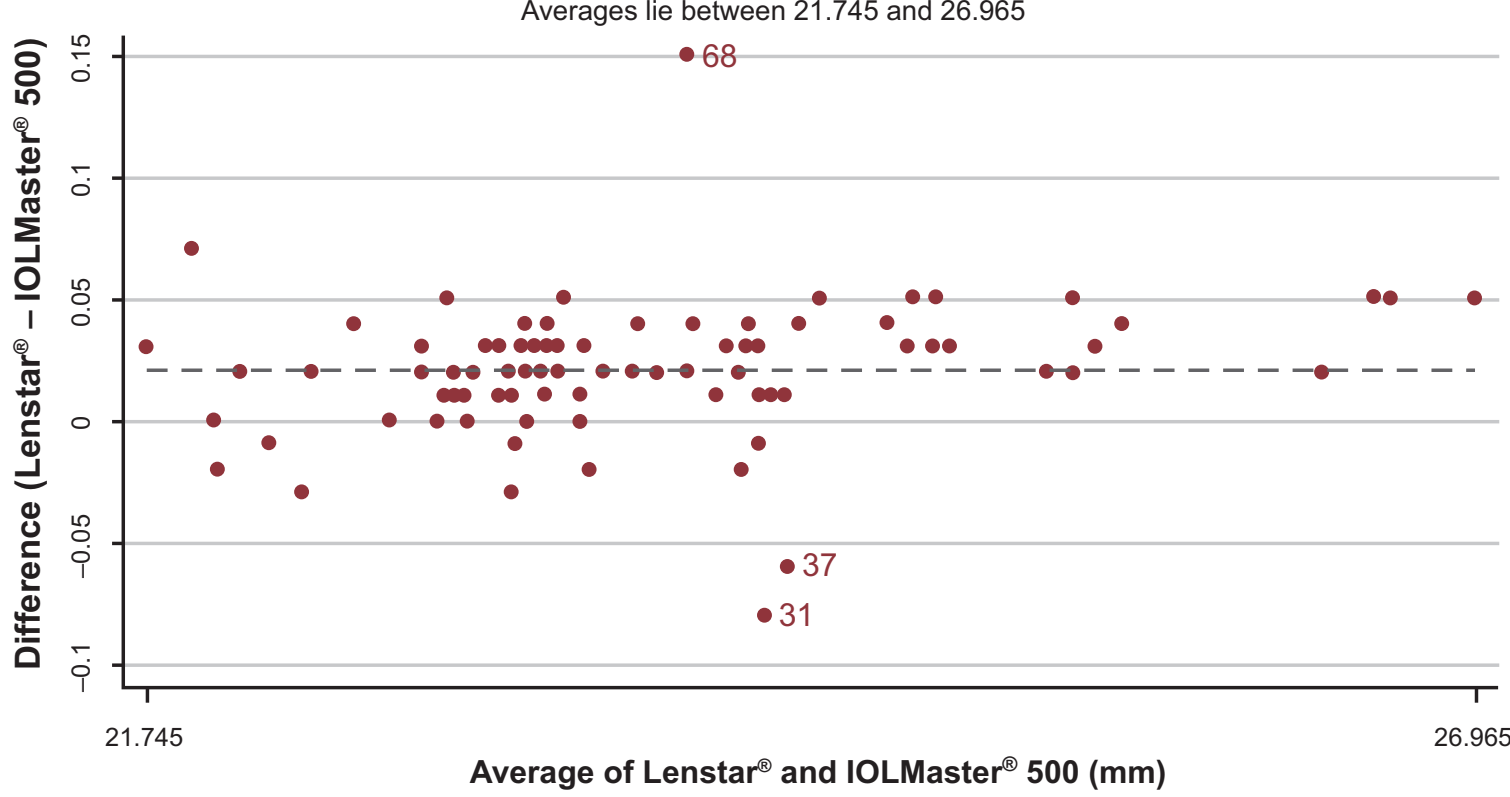

Figure I Axial length difference between IOLMaster ${ }^{\circledR}$ (composite-20 IM) and Lenstar ${ }^{\circledR}$.

Notes: Points outside limits labelled by subject id. Lenstar ${ }^{\circledR}$ standard-5, Haag-Streit AG (Koeniz, Switzerland); IOLMaster ${ }^{\circledR}$ composite-5; IOLMaster $^{\circledR}$ composite-20, Carl $^{2}$ Zeiss Meditec AG (Jena, Germany). The dotted line signifies the mean difference in axial length ( 0.021$)$.

Abbreviation: id, identification number.

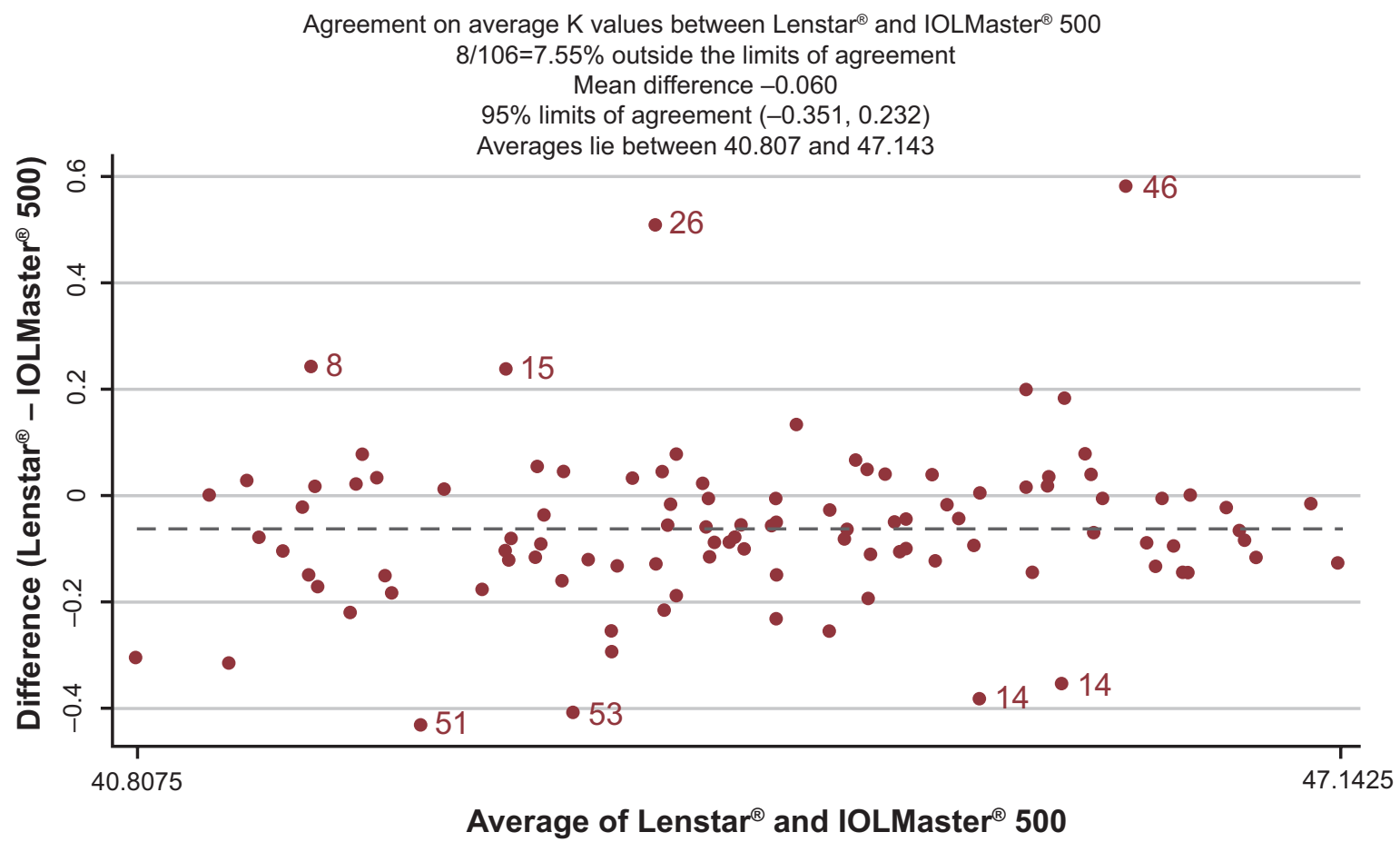

Figure 2 Corneal curvature (average K) difference between IOLMaster ${ }^{\circledR}$ and Lenstar $^{\circledR}$.

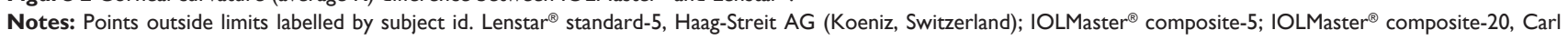
Zeiss Meditec AG (Jena, Germany). The dotted line signifies the mean difference in average K values $(-0.060)$.

Abbreviation: id, identification number. 


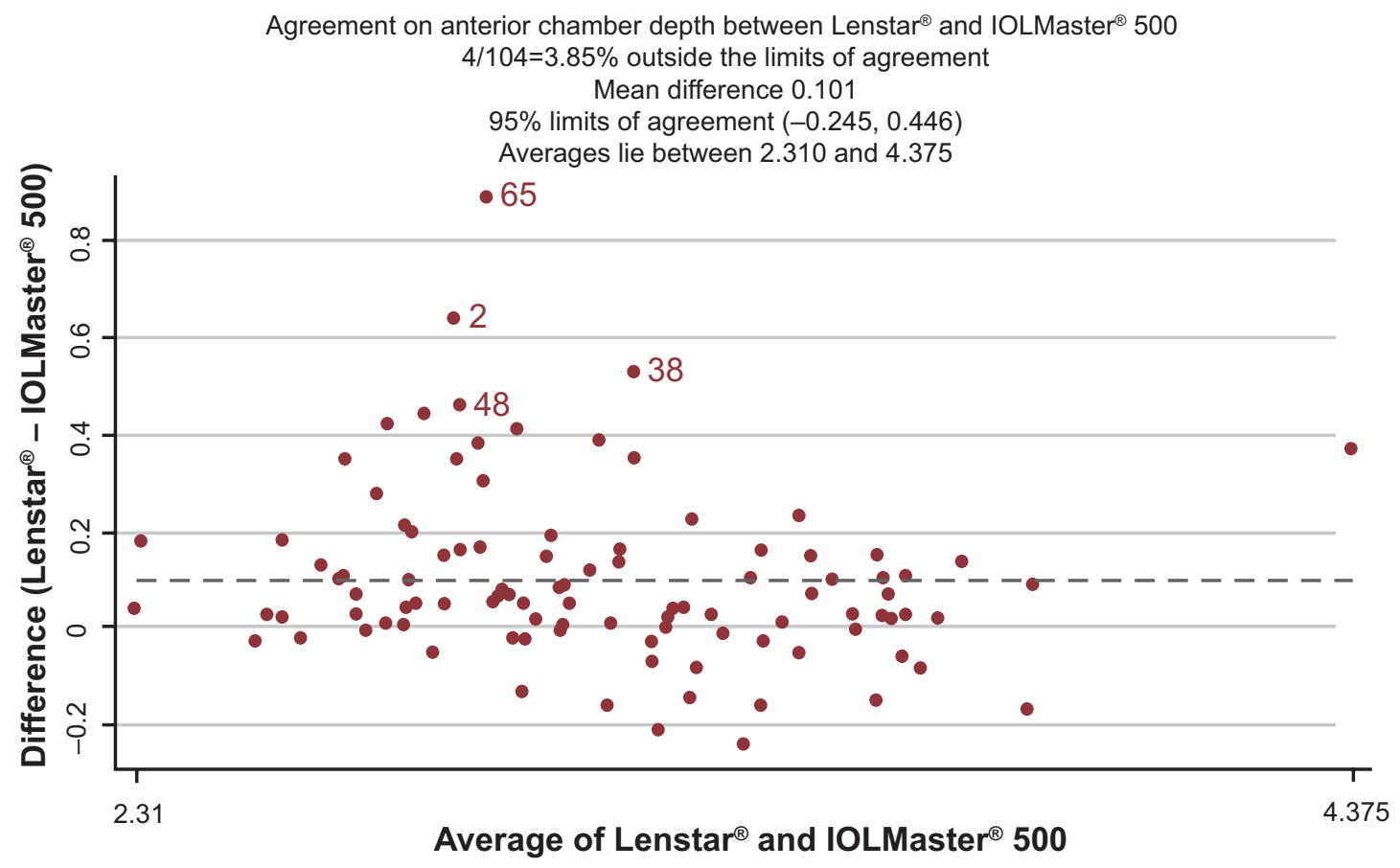

Figure 3 Anterior chamber depth difference between IOLMaster ${ }^{\circledast}$ and Lenstar ${ }^{\circledast}$.

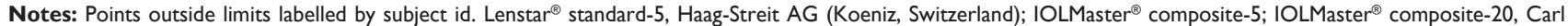
Zeiss Meditec AG (Jena, Germany). The dotted line signifies the mean difference in anterior chamber depth $(0.10 \mathrm{I})$.

Abbreviation: id, identification number.

cataract, we found the IOLMaster ${ }^{\circledR} 500$ was more reliable and repeatable with better penetration than the Lenstar $^{\circledR}$ in those patients with dense cataracts.

Hill et $\mathrm{al}^{20}$ reported success in acquiring the $\mathrm{AL}$ in $92.6 \%$ of eyes using the composite- 5 method and a success rate of $96.3 \%$ using the composite- 20 method using the IOLMaster ${ }^{\circledR}$ 5.0 with version 5 software. The presence of PSC cataracts impacted the ability of all acquisition methods to acquire $\mathrm{AL}$, and the effect was most apparent with denser PSC cataracts. AL acquisition success rates were slightly lower in our study (83.8\% and $92.4 \%$ for the composite-5 IM and composite-20 IM methods, respectively) compared with Hill et al. ${ }^{20}$ This disparity may be attributable to methodological differences (ie, sample size, cataract grades). Whereas
Hill et al performed AL measurements around the areas of the cataract perceived to be the least dense, our study protocol called for AL measurement at the center of the cataract regardless of density.

Buckhurst et al ${ }^{18}$ reported a $9 \%$ to $10 \%$ acquisition failure rate in cataractous eyes with both the Lenstar ${ }^{\circledR 8}$ and the IOLMaster ${ }^{\circledR}$ using version 5 software, and attributed AL acquisition failures to dense media opacities (classification and grading of cataract according to morphology and density was not performed). Our study results add to the literature as we found the composite-5 IM method was significantly affected by nuclear color and cortical grades, while the standard-5 LS method was significantly affected by PSC and cortical grades.

Table 3 Comparison of parameter measurements

\begin{tabular}{llll}
\hline Parameter & IOLMaster $^{\circledR} \mathbf{5 0 0}$ & Lenstar $^{\circledR}$ & Difference Lenstar $^{\circledR}-$ IOLMaster \\
\hline ACD $(\mathrm{mm})$ & & & \\
Mean \pm SD & $3.05 \pm 0.39$ & $3.15 \pm 0.36$ & $0.10 \pm 0.18$ \\
Range & 2.23 to 4.19 & 2.33 to 4.56 & -0.24 to 0.89 \\
P-value & & & $<0.001$ \\
Average K & & & \\
Mean \pm SD & $44.12 \pm 1.54$ & $44.06 \pm 1.56$ & $-0.06 \pm 0.15$ \\
Range & 40.96 to 47.21 & 40.66 to 47.08 & -0.43 to 0.58 \\
P-value & & & $<0.001$
\end{tabular}

Notes: Lenstar ${ }^{\circledR}$ standard-5, Haag-Streit AG (Koeniz, Switzerland); IOLMaster ${ }^{\circledR}$ 500, Carl Zeiss Meditec AG (Jena, Germany).

Abbreviations: $A C D$, anterior chamber depth; average $K$, corneal curvature; $S D$, standard deviation. 
Table 4 Comparison of axial length measurements

\begin{tabular}{|c|c|c|c|}
\hline Difference* & $\begin{array}{l}\text { Difference (Lenstar } \\
\text { standard-5 } \\
\text { LS - IOLMaster } \\
\text { composite-5 IM) }\end{array}$ & $\begin{array}{l}\text { Difference (Lenstar } \\
\text { standard-5 } \\
\text { LS - IOLMaster } \\
\text { composite-20 IM) }\end{array}$ & $\begin{array}{l}\text { Difference (IOLMaster } \\
\text { composite-5 } \\
\text { IM - IOLMaster } \\
\text { composite-20 IM) }\end{array}$ \\
\hline \multicolumn{4}{|l|}{$\mathrm{AL}(\mathrm{mm})$} \\
\hline Mean \pm SD & $0.03 \pm 0.03$ & $0.02 \pm 0.03$ & $-0.0 \pm 0.03$ \\
\hline Range & -0.06 to 0.19 & -0.08 to 0.15 & -0.20 to 0.08 \\
\hline$P$-value paired-t comparing means & $<0.001$ & $<0.001$ & 0.840 \\
\hline
\end{tabular}

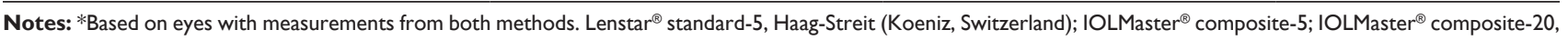
Carl Zeiss Meditec AG (Jena, Germany).

Abbreviations: AL, axial length; SD, standard deviation.

In our study, neither biometer was able to measure an $\mathrm{AL}$ in seven of the 105 eyes. Immersion ultrasound was used to obtain an AL in eight eyes, seven in which $\mathrm{AL}$ was unattainable with either the IOLMaster ${ }^{\circledR} 500$ or Lenstar ${ }^{\circledR}$ and in one eye that the IOLMaster ${ }^{\mathbb{8}} 500$ failed to measure the AL but the Lenstar ${ }^{\circledR}$ succeeded. In this last eye, immersion ultrasound yielded an AL measurement that was $0.51 \mathrm{~mm}$ longer than the Lenstar ${ }^{\mathbb{B}}$-derived AL measurement. In this eye, the Lenstar ${ }^{\circledR}$-derived AL measurement would have resulted in a $2.00 \mathrm{D}$ myopic surprise postoperatively; by using the immersion ultrasound measurement, we achieved a manifest refraction of plano at the 1 month postoperative visit. The error in calculation by the Lenstar ${ }^{\circledR}$ may be attributed to its acquisition algorithm of averaging results of multiple scans to calculate AL. By design, the Lenstar ${ }^{\mathbb{R}}$ includes outlier data in its algorithms that may result in postoperative refractive surprises. We recommend further analysis to confirm this suggestion.

Comparatively, the IOLMaster ${ }^{\circledR} 500$ derives its ALs from a composite acquisition algorithm, which increases the probability of a precise measurement with additional scans. Across all cataract grades, the composite-20 IM achieved a greater ability to acquire AL than the composite-5 IM. In the nine eyes that could not be measured with the Lenstar ${ }^{\mathrm{B}}$ but that could be measured with the IOLMaster ${ }^{\circledR} 500$, at 1 month postoperatively all eyes were within $\pm 0.50 \mathrm{D}$ of the intended refractive target, suggesting the accuracy of the IOLMaster ${ }^{\circledR} 500$.

The standard-5 LS method produced AL measurements that were $0.03 \mathrm{~mm}$ and $0.02 \mathrm{~mm}$ longer than the composite- 5 IM and composite-20 IM methods, respectively. Hoffer et al ${ }^{1}$ and Buckhurst et a ${ }^{18}$ also reported slightly longer $(+0.026 \mathrm{~mm}$ and $+0.01 \mathrm{~mm}$, respectively) AL measurements, while Rabsilber et $a{ }^{17}$ found that the Lenstar ${ }^{\circledR}$ and the IOLMaster ${ }^{\mathbb{B}}$ produced similar AL measurement lengths in cataractous eyes. The reason for these discrepancies is unclear; however, the mean differences are very low and likely clinically insignificant.
Our findings support previous studies that also reported higher ACD values determined with the Lenstar ${ }^{\circledR}$ compared with the IOLMaster ${ }^{\circledR} 500 .^{1,17,18}$ The variation in technology used may account for this. Lenstar ${ }^{\circledR}$ uses laser interferometry to determine all axial dimensions of the eye, including ACD, whereas the IOLMaster ${ }^{\circledR} 500$ uses lateral slit illumination and video image analysis to evaluate the distance between the cornea and the anterior surface of the crystalline lens, ${ }^{17}$ which may explain these differences. The difference in ACD was $0.10 \pm 0.18$ (range, -0.24 to 0.89 ), which could indicate that different results may be obtained using a formula that uses the ACD as one parameter (ie, Haigis or Olsen).

The Lenstar ${ }^{\circledR}$ produced slightly flatter $\mathrm{K}$ readings compared with the IOLMaster ${ }^{\circledR} 500$ in our study $(-0.06 \pm 0.15 \mathrm{D})$, which again supports Hoffer et al. ${ }^{1}$ The differences in K readings (see Table 3) may indicate that different IOL calculation results could be obtained.

We noted that the total measurement time was faster with the IOLMaster 500 (average, 4.50 minutes) compared to the Lenstar ${ }^{\circledR}$ (average, 5.88 minutes), even though the IOLMaster $^{\circledR} 500$ requires extra time to obtain $\mathrm{K}, \mathrm{ACD}$, and $\mathrm{CD}$ readings. Despite the fact that the Lenstar ${ }^{\circledR}$ device measures all parameters in a single process, it took $25 \%$ longer (a difference of 1.38 minutes) to acquire measurements than the IOLMaster ${ }^{\circledR} 500 \mathrm{did}(P<0.001)$. Moreover, the shorter acquisition time with the IOLMaster ${ }^{\circledR} 500$ may translate into improved clinical efficiency and greater workflow.

This study is not without limitations. Our study population comprised mixed cataracts as defined by the LOCS III classification scheme, reflective of the real-world clinical setting, but may be a potential limitation to the study. Ideally, detecting associations between one specific class of cataracts and the ability of a biometric assessment of AL would entail enrollment of eyes with only the desired morphologic characteristics. Eyes also can be subdivided according to the desired morphologic characteristics (ie, PSC <4.2) with all other variables (eg, nuclear color, nuclear opalescence, 
and cortical grade $<0.1)$ to isolate the effect of the desired cataract characteristic. Our sample size was also not large enough to set up a regression model in which potentially confounding data could be better controlled.

In conclusion, $\mathrm{ACD}$ and average $\mathrm{K}$ readings were statistically different between the two optical biometers, although these differences were not clinically significant in terms of refractive outcomes. AL measurements using the IOLMaster ${ }^{\circledR}$ 500 yielded higher acquisition success rates compared with the Lenstar LS $900^{\circledR}$. In this study, the IOLMaster ${ }^{\circledR} 500$ was more likely to acquire the AL through denser cataracts, requiring fewer immersion studies. Greater accuracy and efficiency in determining the AL should translate to more reproducible measurements, improved workflow and, therefore, improved clinical outcomes.

\section{Acknowledgments}

Equipment was provided by each manufacturer free of charge. AE has received speaker fees from Carl Zeiss Meditec Inc., Dublin, CA, USA, but has no financial or proprietary interest in any material or method mentioned. Michelle Dalton, ELS, provided editorial assistance.

\section{Disclosure}

The author reports no conflicts of interest in this work.

\section{References}

1. Hoffer KJ, Shammas HJ, Savini G. Comparison of 2 laser instruments for measuring axial length. $J$ Cataract Refract Surg. 2010;36(4):644-648.

2. Olsen T. Sources of error in intraocular lens power calculation. J Cataract Refract Surg. 1992;18(2):125-129.

3. Drexler W, Findl O, Menapace R, et al. Partial coherence interferometry: a novel approach to biometry in cataract surgery. Am J Ophthalmol. 1998; 126(4):524-534.

4. Kiss B, Findl O, Menapace R, et al. Biometry of cataractous eyes using partial coherence interferometry: clinical feasibility study of a commercial prototype I. J Cataract Refract Surg. 2002;28(2):224-229.

5. Kiss B, Findl O, Menapace R, et al. Refractive outcome of cataract surgery using partial coherence interferometry and ultrasound biometry: clinical feasibility study of a commercial prototype II. $J$ Cataract Refract Surg. 2002;28(2):230-234.
6. Connors R, Boseman P, Olson RJ. Accuracy and reproducibility of biometry using partial coherence interferometry. $J$ Cataract Refract Surg. 2002;28(2):235-238.

7. Rajan MS, Keilhorn I, Bell JA. Partial coherence laser interferometry vs conventional ultrasound biometry in intraocular lens power calculations. Eye (Lond). 2002;16(5):552-556.

8. Eleftheriadis H. IOLMaster biometry: refractive results of 100 consecutive cases. Br J Ophthalmol. 2003;87(8):960-963.

9. Olsen T. Improved accuracy of intraocular lens power calculation with the Zeiss IOLMaster. Acta Ophthalmol Scand. 2007;85(1):84-87.

10. Vogel A, Dick HB, Krummenauer F. Reproducibility of optical biometry using partial coherence interferometry: intraobserver and interobserver reliability. J Cataract Refract Surg. 2001;27(12):1961-1968.

11. Németh J, Fekete O, Pesztenlehrer N. Optical and ultrasound measurement of axial length and anterior chamber depth for intraocular lens power calculation. J Cataract Refract Surg. 2003;29(1):85-88.

12. Lam AK, Chan R, Pang PC. The repeatability and accuracy of axial length and anterior chamber depth measurements from the IOLMaster. Ophthalmic Physiol Opt. 2001;21(6):477-483.

13. Findl O, Kriechbaum K, Sacu S, et al. Influence of operator experience on the performance of ultrasound biometry compared to optical biometry before cataract surgery. J Cataract Refract Surg. 2003;29(10):1950-1955.

14. Siahmed K, Muraine M, Brasseur G. [Optic biometry in intraocular lense calculation for cataract surgery. Comparison with usual methods]. J Fr Ophtalmol. 2001;24(9):922-926. French.

15. Packer M, Fine IH, Hoffman RS, Coffman PG, Brown LK. Immersion A-scan compared with partial coherence interferometry: outcomes analysis. J Cataract Refract Surg. 2002;28(2):239-242.

16. Shammas HJ, Chan S. Precision of biometry, keratometry, and refractive measurements with a partial coherence interferometry-keratometry device. J Cataract Refract Surg. 2010;36(9):1474-1478.

17. Rabsilber TM, Jepsen C, Auffarth GU, Holzer MP. Intraocular lens power calculation: clinical comparison of 2 optical biometry devices. $J$ Cataract Refract Surg. 2010;36(2):230-234.

18. Buckhurst PJ, Wolffsohn JS, Shah S, Naroo SA, Davies LN, Berrow EJ. A new optical low coherence reflectometry device for ocular biometry in cataract patients. Br J Ophthalmol. 2009;93(7):949-953.

19. Holzer MP, Mamusa M, Auffarth GU. Accuracy of a new partial coherence interferometry analyser for biometric measurements. $\mathrm{Br} J$ Ophthalmol. 2009;93(6):807-810.

20. Hill W, Angeles R, Otani T. Evaluation of a new IOLMaster algorithm to measure axial length. J Cataract Refract Surg. 2008;34(6):920-924.

21. Chylack LT, Wolfe JK, Singer DM, et al. The Lens Opacities Classification System III. The Longitudinal Study of Cataract Study Group. Arch Ophthalmol. 1993;111(6):831-836.

22. Tehrani M, Krummenauer F, Blom E, Dick HB. Evaluation of the practicality of optical biometry and applanation ultrasound in 253 eyes. J Cataract Refract Surg. 2003;29(4):741-746.

23. Freeman G, Pesudovs K. The impact of cataract severity on measurement acquisition with the IOLMaster. Acta Ophthalmol Scand. 2005;83(4):439-442.
Clinical Ophthalmology

\section{Publish your work in this journal}

Clinical Ophthalmology is an international, peer-reviewed journal covering all subspecialties within ophthalmology. Key topics include: Optometry; Visual science; Pharmacology and drug therapy in eye diseases; Basic Sciences; Primary and Secondary eye care; Patient Safety and Quality of Care Improvements. This journal is indexed on Submit your manuscript here: http://www.dovepress.com/clinical-ophthalmology-journal
Dovepress

PubMed Central and CAS, and is the official journal of The Society of Clinical Ophthalmology (SCO). The manuscript management system is completely online and includes a very quick and fair peer-review system, which is all easy to use. Visit http://www.dovepress.com/ testimonials.php to read real quotes from published authors. 